\title{
Discrete Element Models of Soil-Geogrid Interaction
}

\author{
Alina Irsainova ${ }^{1}$, Marcos Arroyo $^{2}$, and Jong-Ryeol Kim ${ }^{1(\bowtie)}$ \\ ${ }^{1}$ Nazarbayev University, Astana 010000, Kazakhstan \\ jong. kim@nu. edu.kz \\ 2 Universitat Politècnica de Catalunya, 08034 Barcelona, Spain
}

\begin{abstract}
Geogrids are the geosynthetics of choice for soil reinforcement applications. To evaluate the efficiency of geogrid reinforcement, several methods are used including field tests, laboratory tests and numerical modeling. Field studies consume long period of time and conducting these investigations may become highly expensive because of the need for real-size structures. Laboratory studies present also significant difficulties: large-size testing machines are required to accommodate realistic geogrid designs. The discrete element method (DEM) may be used as a complementary tool to extend physical testing databases at lower cost. Discrete element models do not require complex constitutive formulations and may be fed with particle scale data (size, strength, shape) thus reducing the number of free calibration parameters. Discrete element models also are well suited to problems in which large displacements are present, such as geogrid pullout. This paper reviews the different approaches followed to model soil-geogrid interaction in DEM and presents preliminary results from pull-out conditions.
\end{abstract}

Keywords: Discrete element method (DEM) $\cdot$ Soil reinforcement $\cdot$ Geogrids

\section{Introduction}

\subsection{Geogrids}

Geosynthetics are synthetically manufactured products used with soil, rock, and earth so overcome civil engineering problems. Geosynthetics can be used in a wide spectrum of fields such as transportation, geotechnical, environmental, hydraulics, and private development [1].

Geogrids are one of the types of geosynthetics that are quickly growing in usage. Its structure consists of plastic ribs forming big apertures. Due to its open-like structure, it can be used for reinforcement and stabilization. Transverse and longitudinal ribs of the geogrids are manufactured from high-modulus polymers; therefore, the strength of geogrid ribs is higher than the strength of geotextiles. Transverse members of the geogrids serve as an abutment or anchor due to their location parallel to the face of structure. Therefore, the main function of longitudinal ribs is to keep the transverse ribs in position [2]. The opening size of geogrids is sufficient enough to allow soil contact and interlocking between particles. Geogrid reinforcement provides higher shear strength of soil mass and higher load bearing capacity. Geogrids are also helpful in 
preventing soil erosion. Moreover, use of geogrids in construction reflects other advantages such as ease of construction, high durability, resistance to environmental issues, availability of the material, and low cost [3].

\subsection{Geogrid Modeling Methods}

Modeling of geogrids can be categorized as soil-inclusion problems. Applying finite element method (FEM) for such case is widely practiced [4, 5]. However, using FEM to model soil-inclusion problems faces difficulties in the definition of crucial parameters that represent grid-soil interaction. Application of discrete element method (DEM) may be useful, particularly for cases involving large sized granular materials. There are several studies that describe conventional method of modeling representing soil and soil inclusion as rigid spherical particles [6]. Some studies develop soilinclusion model by using mix of methods: where soil was modeled by discrete element (DE) and geogrid was modeled by finite element (FE) [7]. A summary example of geogrid modeling methods is given in Table 1 .

Table 1. Summary of geogrid modeling methods.

\begin{tabular}{l|l|l|l}
\hline$\#$ & Modeling approaches & Applications & Refs. \\
\hline 1 & $\begin{array}{l}\text { Model by using FEM: where } \\
\text { both soil and geogrid was } \\
\text { modeled by finite element }\end{array}$ & $\begin{array}{l}\text { Pull-out behavior of the model } \\
\text { was investigated }\end{array}$ & $\begin{array}{l}\text { Sugimoto and } \\
\text { Alagiyawanna [4]; } \\
\text { Khedkar and } \\
\text { Mandal [5] }\end{array}$ \\
\hline 2 & $\begin{array}{l}\text { DEM model representing soil } \\
\text { and soil inclusion as rigid } \\
\text { spherical particles }\end{array}$ & $\begin{array}{l}\text { Cyclic triaxial loading } \\
\text { simulation with spherical } \\
\text { ballast particles }\end{array}$ & $\begin{array}{l}\text { McDowell et al. } \\
\text { [6] }\end{array}$ \\
\hline 3 & $\begin{array}{l}\text { DEM-FEM models: where soil } \\
\text { was modeled by spherical } \\
\text { discrete element and geogrid } \\
\text { was modeled by finite element } \\
\text { (FE) }\end{array}$ & $\begin{array}{l}\text { Pull-out test was performed to } \\
\text { define relationships between } \\
\text { pull-out force and } \\
\text { displacements }\end{array}$ & Tran et al. [7] \\
\hline 4 & $\begin{array}{l}\text { DEM model by representing } \\
\text { geogrids as deformable } \\
\text { cylinders according to the } \\
\text { Minkowski sum concept and } \\
\text { representing soil as spherical } \\
\text { particles }\end{array}$ & $\begin{array}{l}\text { Pull-out test was performed in } \\
\text { order to check effectiveness of } \\
\text { the model }\end{array}$ & Thoeni et al. [8] \\
\hline
\end{tabular}

\section{Numerical Modeling}

\subsection{Numerical Modeling Method}

A method to model geogrid-soil interactions through representing geogrids as deformable cylinders according to the concept by Minkowski sum has been recently proposed by Thoeni et al. [8]. Main components of Minkowski sum include rigid 
spheres (Fig. 1a) and cylinders represented by sphere and line (Fig. 1b). Each rib of the grid can be modeled by one or more cylinders depending on geometry of grid.

Contacts between each component are treated as sphere-sphere interconnection allowing to use basic mathematical formulation for contact forces.

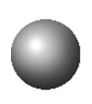

(a)

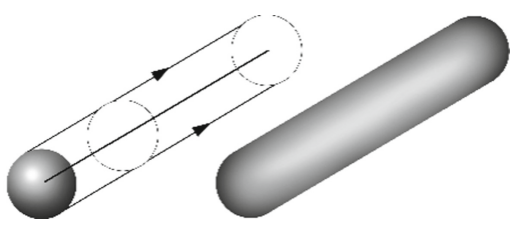

(b)

Fig. 1. Minkowski sum components: (a) sphere and (b) cylinder [8]

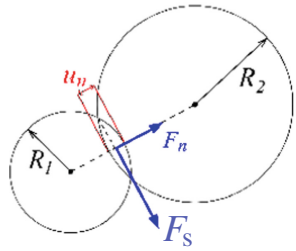

(a)

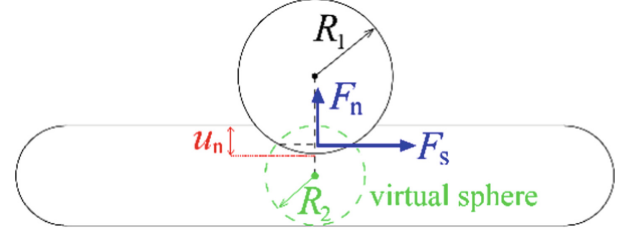

(b)

Fig. 2. Contact forces between components: (a) sphere-sphere and (b) sphere and virtual sphere of cylinder or pfacet [8]

\subsection{Inter-particle Contact Law}

A linear contact stiffness law and Mohr-Coulomb friction were used in the software to describe inter-particle interaction. This law implements the classical linear elasticplastic law from Cundall Strack [9]. The normal force is (with the convention of positive tensile forces) $F_{n}=\min \left(k_{n} u_{n}, 0\right)$, where $u_{n}$ is the normal distance between two spheres. The shear force is $\mathrm{F}_{\mathrm{s}}=\mathrm{k}_{\mathrm{s}} \mathrm{u}_{\mathrm{s}}$, where $\mathrm{u}_{\mathrm{s}}$ is the relative shear displacement. The plasticity condition defines the maximum value of the shear force: $F_{s}(\max )=F_{n}$ $\tan (\varphi)$, with $\varphi$ the friction angle. The linear contact model stiffness is derived from the normal and shear stiffness $\mathrm{k}_{\mathrm{n}}$ and $\mathrm{k}_{\mathrm{s}}$ assigned to the contacting objects. Linear contact model represents two contacting objects to be in series; hence, normal secant stiffness of contact is defined by following equation:

$$
k_{n}=\frac{k_{n 1} k_{n 2}}{k_{n 1}+k_{n 2}}=\frac{2 E_{1} R_{1} E_{2} R_{2}}{E_{1} R_{1}+E_{2} R_{2}}
$$

where, $\mathrm{k}_{\mathrm{n} 1}, \mathrm{k}_{\mathrm{n} 2}=$ normal stiffness of contacting objects. Whereas shear tangent stiffness of the contact is defined by: 


$$
\mathrm{k}_{\mathrm{s}}=\frac{\mathrm{k}_{\mathrm{s} 1} \mathrm{k}_{\mathrm{s} 2}}{\mathrm{k}_{\mathrm{s} 1}+\mathrm{k}_{\mathrm{s} 2}}=\frac{2 \mathrm{E}_{1} \mathrm{R}_{1} v_{1} \mathrm{E}_{2} \mathrm{R}_{2} v_{2}}{\mathrm{E}_{1} \mathrm{R}_{1} v_{1}+\mathrm{E}_{2} \mathrm{R}_{2} v_{2}}
$$

where, $\mathrm{k}_{\mathrm{s} 1}, \mathrm{k}_{\mathrm{s} 2}=$ shear stiffness of contacting objects, $\mathrm{E}_{1}, \mathrm{E}_{2}=$ Young's modulus, $\mathrm{R}_{1}$, $\mathrm{R}_{2}=$ radii of the contacting spheres, and $v_{1}, v_{2}=$ Poisson's ratio. When a soil particle contacts a grid component the same formulas apply, but the grid is assigned the radius of the virtual inscribed sphere (see Fig. 2(b)).

\section{Results and Discussion}

Ongoing work is directed to apply the discussed geogrid modeling technique in realistic laboratory configurations. A pull-out test was initially modeled in order to observe the potential of the approach chosen. The contact properties of soil and geogrid material are assumed to be the same (Table 2). Note that, for simplicity, no rolling friction was included in the contact model. Square grid mesh of $9.5 \mathrm{~cm} \times 9.5 \mathrm{~cm}$ dimensions with $1 \mathrm{~cm}$ openings was introduced to the model (Fig. 3a). Pull-out of the grid for cubic soil matrix with sides of $10 \mathrm{~cm}$ was performed applying a constant velocity of $0.06 \mathrm{~m} / \mathrm{s}$ to the grid. All numerical simulation was performed using Yade software [10].

Table 2. Summary of material properties.

\begin{tabular}{l|l}
\hline Parameter & Value \\
\hline Young's modulus, $E$ & $5000 \mathrm{kPa}$ \\
\hline Density, $\rho$ & $2650 \mathrm{~kg} / \mathrm{m}^{3}$ \\
\hline Poisson's ratio, $v$ & 0.3 \\
\hline Friction angle, $\varphi$ & $20^{\circ}$ \\
\hline
\end{tabular}

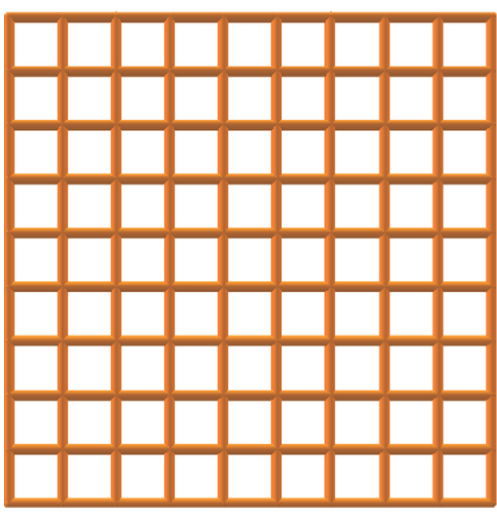

(a)

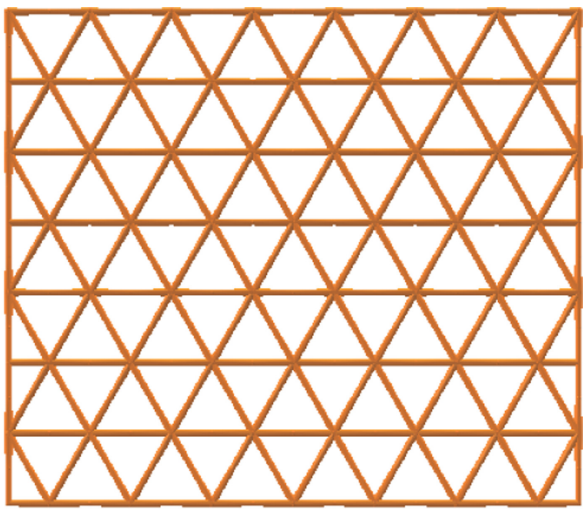

(b)

Fig. 3. Geogrid mesh: (a) rectangular and (b) triangular 
Figure 4 shows a pull-out test at several stages, with the grid at different positions. Figure 4(a) shows when the displacement of a grid at the initial stage $(\Delta x=0)$, while Fig. 4(b) and (c) present pull-out at the intermediate stage $(\Delta x=4.75 \mathrm{~cm})$ and total pullout $(\Delta x=9.5 \mathrm{~cm})$ respectively. The entrapment of soil particles can be observed as grey soil columns became mixed with green columns as geogrid is being pulled-out. This is indicative of the interlocking properties of the grid because soil particles are captured in the grid openings and while it is pulled out, the particles move along the movement direction.

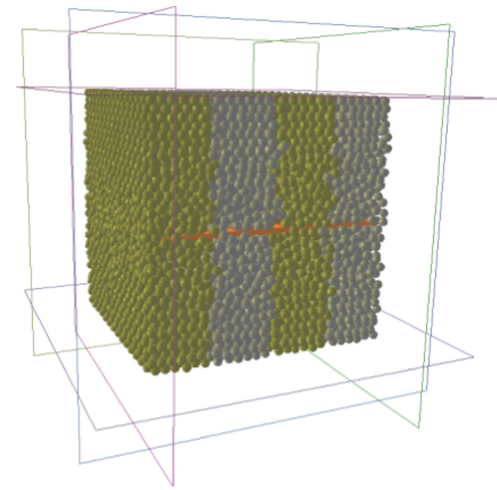

(a)

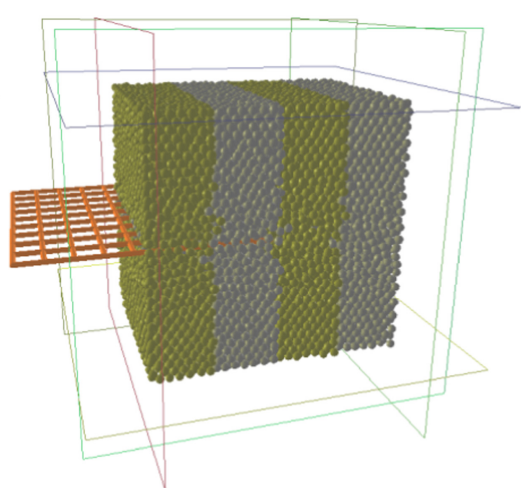

(b)

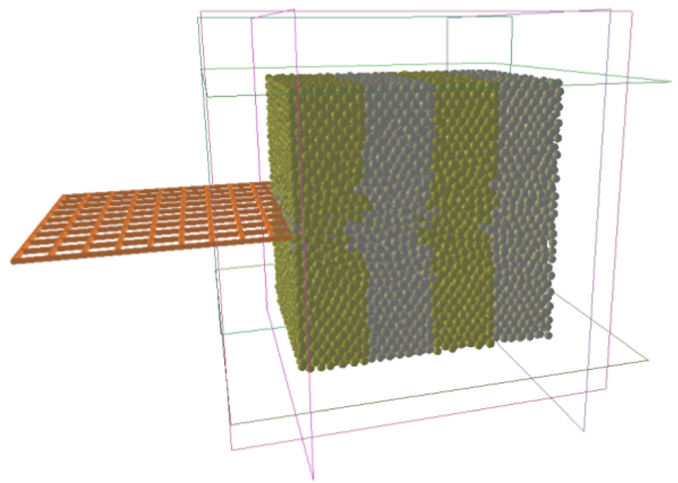

(c)

Fig. 4. Pull-out of a grid: (a) $\Delta \mathrm{x}=0$, (b) $\Delta \mathrm{x}=4.75 \mathrm{~cm}$ and (c) $\Delta \mathrm{x}=9.5 \mathrm{~cm}$

A parametric study was conducted, in which the grid pull-out was performed under different conditions. The parameters explored included the vertical confining pressure at the top wall of the box, size of soil particles and the shape of the grid pulled out. The corresponding values of the parameters are presented in Table 3. It is noted that a uniform sized particle distribution was used in all cases. The schematic view of $10 \mathrm{~cm} \times 8.7 \mathrm{~cm}$ triangular geogrid can be seen in Fig. 3(a) and its geometry is more complex compared to the rectangular. Triangles of the grid are equilateral with the sides of $1.43 \mathrm{~cm}$ and vertical components at both sides of the grid are $1.24 \mathrm{~cm}$. 
Table 3. Range of parameters considered in the study.

\begin{tabular}{l|l}
\hline Parameter & Value \\
\hline Confining pressure, $\mathrm{P}(\mathrm{kPa})$ & 75,150 and 300 \\
\hline Radius of soil grains, $\mathrm{r}(\mathrm{m})$ & $0.001,0.0015$ and 0.0025 \\
\hline Shape of geogrid & Rectangular and triangular \\
\hline
\end{tabular}

The resultant graph of pull-out force versus displacement is given in Fig. 5 for various confining pressure conditions. This case considers rectangular geogrid with middle $(0.0015 \mathrm{~m})$ soil particle dimension. The figure shows that pull-out response slightly increases with increasing vertical confining stress of $75 \mathrm{kPa}, 150 \mathrm{kPa}$ and $300 \mathrm{kPa}$. Average values of pull-out force are $20.11 \mathrm{~N}, 28.05 \mathrm{~N}$ and $31.20 \mathrm{~N}$ respectively. Interestingly there seems to be very little effect on the pullout force of the reduction of inserted grid length in the specimen; as long as there is one transversal rib in the box the pull-out force average is closely maintained.

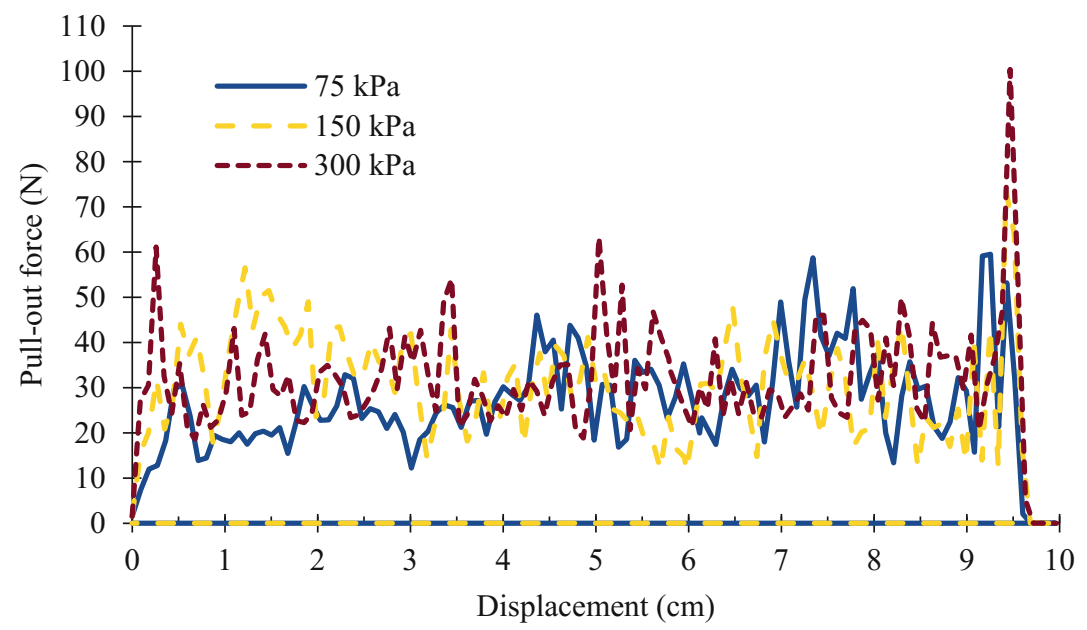

Fig. 5. Pull-out response of square geogrid: $r=0.0015 \mathrm{~m}$

Another figure was built to illustrate variance of response of geogrid pull-out according to different shapes of geogrid. Figure 6 represents the case with vertical confining stress of $150 \mathrm{kPa}$ and with soil grain radius of $0.0025 \mathrm{~m}$. The figure shows that pull-out response for the rectangular grid is higher than triangular grid case, at least until a large displacement has been achieved. Average pull-out forces for rectangular and triangular grid shapes are $36.66 \mathrm{~N}$ and $28.05 \mathrm{~N}$ respectively. 


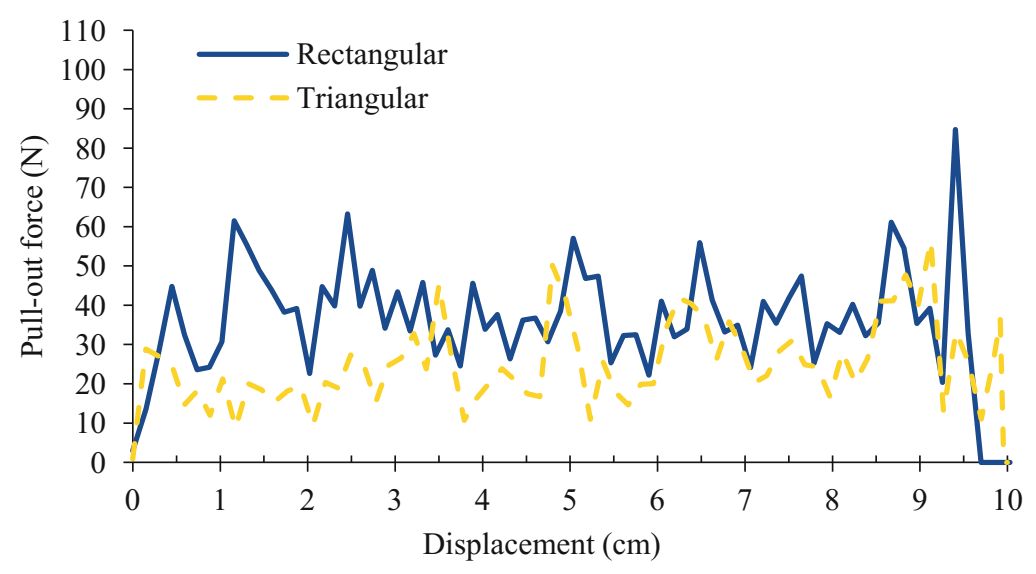

Fig. 6. Pull-out of geogrids: $\mathrm{P}=150 \mathrm{kPa}$ and $\mathrm{r}=0.0025 \mathrm{~m}$

Average pull-out force values for each case in the study are shown in Table 4. As expected, for all sizes of soil grains the pull-out response of the grid is higher for increased vertical confinement. In order to quantify variation of the pull-out response results, coefficient of variation values were estimated. Table 5 includes coefficient of variation for different particles sizes and for varied vertical confining stress. As a result, variation coefficient decreases with the decreasing particle size for each confinement scenario. This indicates that variation of the pull-out response is smaller for smaller grain size which leads to more precise results. As the model becomes more continuous the variance of the results related to the average value diminishes.

Table 4. Average pull-out force values with different parameters.

\begin{tabular}{l|l|l|l|l}
\hline \multirow{2}{*}{$\begin{array}{l}\text { Confining } \\
\text { pressure }(\mathrm{kPa})\end{array}$} & \multicolumn{3}{|l|}{ Radius of soil particles $(\mathrm{m})$} & \multirow{2}{*}{$\begin{array}{l}\text { Triangular shape } \\
(\mathrm{r}=0.0025 \mathrm{~m})\end{array}$} \\
\cline { 2 - 4 } & 0.0025 & 0.0015 & 0.0010 & \\
\hline 75 & 26.29 & 20.11 & 41.32 & 20.11 \\
\hline 150 & 36.66 & 28.05 & 42.41 & 28.05 \\
\hline 300 & 43.56 & 31.20 & 44.51 & 39.23 \\
\hline
\end{tabular}

Table 5. Coefficient of variation of pull-out force with different parameters.

\begin{tabular}{l|l|l|l}
\hline \multirow{2}{*}{ Confining pressure $(\mathrm{kPa})$} & \multicolumn{3}{|l}{ Radius of soil particles $(\mathrm{m})$} \\
\cline { 2 - 4 } & 0.0025 & 0.0015 & 0.0010 \\
\hline 75 & 0.543 & 0.445 & 0.242 \\
\hline 150 & 0.434 & 0.381 & 0.234 \\
\hline 300 & 0.413 & 0.406 & 0.230 \\
\hline
\end{tabular}

